\title{
Deploying Mobiles to Achieve Collaboration Among Learners during COVID-19 Induced Lockdowns
}

\author{
Servious Mbiza \\ *Faculty of Technology, Zimbabwe Open University \\ DOI: 10.29322/IJSRP.11.07.2021.p11545 \\ http://dx.doi.org/10.29322/IJSRP.11.07.2021.p11545
}

\begin{abstract}
The outbreak of the COVID-19 pandemic, and the measures put in place by governments to contain its spread have shaken the traditional ways of offering education the world over. Developing countries were hit hard because most of them were still depending on wall and chalkboard classrooms to conduct classes. Lockdowns and social distancing measures left schools and colleges unable to conduct classes thus affecting thousands and thousands of learners. This situation has prompted both educators and technologists to seek best ways of delivering credible education remotely. Collaborative learning (CL) is an educational approach to teaching and learning that involves groups of learners working together to solve a problem, complete a task, or create a product [1]. It is important to investigate how this can be achieved through mobile technology. A group of 30 learners were broken into 3 smaller groups of 10 and were given tasks to work together. Each member in a group was given a small task to accomplish. Each member was supposed to present to other group members how his or her given task was going to contribute to the accomplishment of the main task. They were supposed to use their mobile phones as the medium for all their interactions. It was found that students mainly used the Whatsup social media platform to interact with their peers. Their reasons for using Whatsup was that it allowed them to easily make their presentations. This research recommends that more experiments with different mobile tools be done to find out which mobile tools are suited to which subject areas.
\end{abstract}

Index Terms- collaborative learning, online collaborative learning, online group work, mobile education, mobile learning

\section{I. INTRODUCTION}

In Zimbabwe, the use of collaborative learning methods using ICT is both new, and it is considered complex by both learners and educators. ICTs are not readily available in learning institutions. Although there are calls to employ ICTs in teaching and learning from all quarters, there is still inadequate budgets to purchase equipment and build the necessary infrastructure to support this development. The lockdowns and other restrictions put on gatherings have found schools and other learning institutions flatfooted. They are unsure, what to do. In most cases this has resulted in individualized and uncoordinated trials on use of technology by educators. Educators must find ways to use technology to teach students locked down in different locations. It is within this context that the use of mobile technology is considered. This study looks at how the constructivist method of collaborative learning can be adopted through mobile technology. The study on mobile technology use is important in Zimbabwe because mobile phones are more accessible than other ICT gadgets. Out of 7.85 billion people on earth there were 5.27 billion unique mobile users at the start of April 2021 [2]. In Zimbabwe there are 13191708 active mobile subscriptions by 2020 [3] against a national population of 13061239 [4] by the same period. This information is startling for a country lacking in most of the economic spheres due to targeted sanctions and other economic ills. The statistics simply tell that we must look to mobile technology to solve the problems of lockdowns affecting educators and learners. When Online Collaborative Learning is appropriately conducted it achieves good results without students necessarily having to physically meet. This reduces the risk of the spread of diseases while at the same time it allows learners to share how they are tackling the diseases. Diseases that require social distancing like Ebola, Flue, Cholera or COVID-19 do not result in the stoppage of learning in a virtual environment. Lecturers are not frightened to conduct classes. Students are not scared to virtually meet and discuss the various topics.

Mobile technology supported collaborative learning begs for more research since there is a mobile revolution taking place right now. Mobility provides new opportunity for education since it provides more chances and allow learners to personalize their collaborative learning process, enhance the social interactions, learn more autonomously, and collaborate with other peers and teachers at anytime and from anywhere, inside and outside the formal collaborative learning context [5]. More recently, a movement within the field of mobile learning has emerged, which focuses on how collaborative learning could be enhanced by applying various mobile technologies [5], [6]. There has been a shift, the world over, from a traditional educational paradigm which is teachercentred to an emergent educational paradigm which considers students as active and central actors in their learning process which promotes, facilitates, and enhances social interactions and collaborations between students [6]. Collaborative learning fits well in student centred learning theories such as constructivism, behaviourism, problem-based learning and social learning.

\section{LITERATURE REVIEW}

Online Collaborative Learning (OCL) is more than group work. Besides learners being in a virtual group, they also bring with them varied experiences which were gained through interacting with both the social and physical environments. The social environment may include the cultural, economic, religious, and political experiences. The physical experiences include climate, weather, landforms, and all sorts of natural phenomenon. Situated learning 
occurs since learners engage one another from their varied individual environments. The way these group members approach problems is informed by their environments. This means that people in virtual groups benefit more from their collaboration than people collaborating from in the same geographical place.

Higher education instructors are beginning to realize the impact of creating communities of learning practice and incorporating social learning into their courses by means of mobile technologies [7]. Deployment of mobile technology brings in more advantages since learners can move from one point to another during tasks. Mobile devices enable learners to carry virtual communities throughout the day while moving from place to place. Mobiles give students opportunities for social discourse, and data capture and recording thus empowering them to organize and reflect on their learning outcomes [8], [9]. Mobile phones can provide authentic, realistic, and relevant learning across context that are physical, technological, conceptual, social, and temporal [10], [11]. The ability of mobile phones to do video live streaming and recording allow learners to really connect with issues that are being learnt. Videos can be streamed, shared, and viewed in real time. The student no longer needs to be at the Victoria Falls in Zimbabwe to view this majestic land phenomenon or be in Egypt to tour the great Pyramids. What is required is to have at least one group member in that place. This one student has the capacity to bring the falls to the class to be viewed, experienced, and studied. Even if the video is not as good as that produced by specialists using specialist equipment, it is likely going to attract attention and generate enough interest among leaners. Other group members can contribute on what they want to see and how they want to view it thus giving learners a very high level of control on what they want to learn together, and how they learn it.

\section{Methodology}

The population for this study were First Year level 1 students in the faculty of technology where the researcher is a lecturer. Thirty Students doing in Software Engineering programme were purposively selected to participate. They were asked to form 3 groups consisting of ten students in each group. These were selected ahead of students in other programmes because the nature of their courses which mainly require students to share tasks. Each of the three groups were asked to create a Whatsup group, adding the researcher as another participant. Each group was given a programming task and each member in the group was supposed to play a part in accomplishing the main task. Before a member does the allocated task, the member was supposed to discuss with group members how he was going to carry out the task. Students were given two weeks to accomplish their tasks. Each group was supposed to select a representative present their solution to the whole class in the third week at their chosen time and using their own chosen method of communicating the result. The students were ordered to use mobile phones from communication, designing and writing code to presentation of the solution. The tasks were given as part of course work for the semester. The researcher observed how the group members were interacting. The researched noted how many times each of the following was used to conduct discussions: text, voice, Whatsup, asynchronous video
STEM students can greatly benefit from collaboration through mobiles. Students from less developed countries can collaborate with students from developed countries to do a project or develop a product. The interactions among learners can be achieved through mobiles since these are readily available and less costly. They can research together, share data, design products together, develop prototypes together and test their products together through simulations. They can even deploy the products in the actual field in which they should work and share videos. It no longer matters where you live, you can still have access to the information you want. You can participate in experiments virtually, adjust the apparatus or variables for the experiment through collaboration with peers on the ground and observe the results from anywhere, anytime in realtime.

Students doing Political Science, Development Studies or any other similar programme may find collaborative learning quite exciting. They can see what is happening in a particular area at the same time, and this can be viewed in real time. This could be political activities or weather conditions. This information can be quickly collated, analyzed and results can quickly be distributed to stakeholders who can immediately use it to avoid dangers or improve their conditions.

International learning is possible through mobiles. Students from the developed northern nations can collaborate with students in the developing south because these students also have access to mobile technology. Unlike other technologies, mobile technology is widely accessible in poor and developing countries. It is the wish of every academic institution to give their students international exposure. In this global networked political economy, engaging students in some form of international learning improves the value of education.

interactions, email or other. The Whatsup social networking platform is the most common in Zimbabwe, though other platforms are also gaining momentum. Students were also asked to respond to a questionnaire on their experiences in using mobile phones as the prescribed technology. The researcher collated his observations and analyzed them. The researcher also tabulated responses from the questionnaire and analyzed them. The following chapter presents the data collected, analyses it and draw conclusions.

\section{DATA PRESENTATION AND ANALYSIS}

The tools used to present members contributions were Whatsup and online video meetings. Basic SMS and E-mail was not used at all. Third students opted for Whatsup with 10 resorting to Whatsup SMS, 6 using Whatsup voice calls and 4 using Whatsup video calls. The use of Whatsup shows that youths are increasingly depending on social media for communication. Basic mobile SMS has become a thing of the past. Email was avoided probably because of the lag it brings in online real-time interactions. No other tools were used. This could reflect lack of knowledge or availability of less powerful mobile phones. 10 students used online video meetings where they could share their screens with 
their peers as they present. Online meetings have become defector platforms for meetings due to COVID-19 restrictions on gatherings. The one third of respondents who utilized the asynchronous online meeting tool could be representative of the trend now, in both formal and informal meetings in Zimbabwe. Table 1 and Fig. 1 below shows how the 30 students presented their respective tasks to other group members.

\begin{tabular}{|l|l|}
\hline Tool used & Frequency \\
\hline basic SMS & 0 \\
\hline Whatsup SMS & 10 \\
\hline Whatsup Video call & 4 \\
\hline Whatsup Voice call & 6 \\
\hline $\begin{array}{l}\text { Asynchronous online } \\
\text { meeting }\end{array}$ & 10 \\
\hline Email & 0 \\
\hline Other & 0 \\
\hline
\end{tabular}

Table 1: Tools used to present

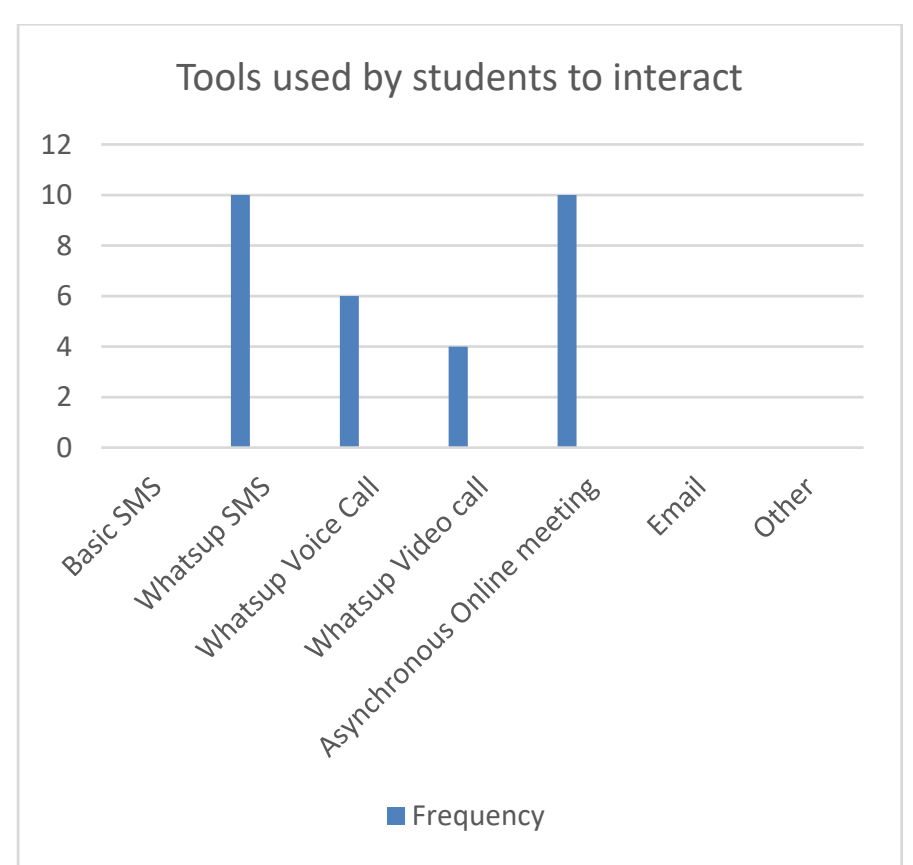

Fig 1: Frequency of mobile tool use

The reason why each student used a particular tool was solicited. A short questionnaire was sent to students to give their input. They were supposed to indicate the tool they used to communicate to other group members, and the reason why they used that tool. The study wanted to investigate what influenced their decision to use the tool. Ten possible reasons for use of a certain tool were suggested, and the respondent was supposed to choose only one reason that influenced him or her most. The frequency of the reasons was measured against each of the four tools used by students to present their tasks.

\section{Whatsup SMS}

The Whatsup SMS was used for three reasons. Out of the 10 students who used it, 4 students said it was easy, another 4 said they did not have sufficient data bundles to use other tools and two said they wanted to share screen shots. Wireless service providers in the country have categorized their bundles, and one can purchase a Whatsup bundle only. Such data bundles cannot access other services on the world Wide Web. The table below shows reasons why the Whatsup SMS tool was used.

\begin{tabular}{|l|l|}
\hline Reason for using the tool & Frequency \\
\hline Easy to use & 4 \\
\hline Wanted to share screen shots & 2 \\
\hline Wanted others to see what I wrote on paper & 0 \\
\hline Wanted to share my mobile screen & 0 \\
\hline Wanted to explain more using voice & 0 \\
\hline I did not have sufficient data bundles & 4 \\
\hline My mobile phone did not have better tools & 0 \\
\hline
\end{tabular}

Table 2: Reasons for using Whatsup SMS tool

\section{Whatsup Voice call}

All the six students who used voice call did it because they thought they could explain more using voice. There are such people who think they can make better presentations using verbal illustrations. However, this can reflect on their inability to utilize other tools. Such students could be assisted to overcome such technical challenges by scaffolding

\section{Whatsup Video call}

One person used video call for the same reason it was used by those who used voice calls. Three students preferred video call because they wanted to show others what they have written on a piece of paper. Written work is still widely used. This is the reason why we still have scanned documents as part of content on the Internet today.

\section{Asynchronous online meeting}

All the 10 students who used asynchronous online meeting did so because they wanted to share the screen. Sharing of screen allows the presenter to move through the slides or windows together with the audience. This brings in such properties as zooming, increasing, and decreasing light which can be done to emphasize certain points.

\begin{tabular}{|l|l|}
\hline Reason for using the tool & Frequency \\
\hline Easy to use & \\
\hline Wanted to share screen shots & \\
\hline Wanted others to see what I wrote on paper & \\
\hline Wanted to share screen & 10 \\
\hline Wanted to explain more using voice & \\
\hline I did not have sufficient data bundles & \\
\hline My mobile phone did not have better tools & \\
\hline
\end{tabular}

Table 3: Reasons for using Online Asynchronous meeting

\section{CONCLUSION AND RECOMMENDATIONS}

The study established that students were able to collaborate through their mobile phones and could easily choose one tool over the other depending on several reasons. The study recommends that more experiments be done to determine which tool is best for a particular class activity in a collaborative learning paradigm. Lockdowns brought about because of the COVID-19 pandemic 
should trigger innovations from technologists and educators that promote mobile collaborative learning. Mobile phones have become part of people's personal lives, so it is logical that we deploy them in education.

\section{REFERENCES}

[1] M. Laal and M. Laal, Collaborative learning: What is it?, Social and Behavioral Sciences 31 (2012) 491 - 495 December 2012

[2] Digital 2021 April Global Statshot Report, Datareportal, (https://datareportal.com/reports/digital-2021-april-global-statshot)m 04 2021

[3] POTRAZ. Abridged Postal \& Telecommunications Sector Performance Report: Fourth Quarter 2020. Postal and Telecommunications Regulatory Authority (Zimbabwe), 2020

[4] Zimbabwe National Statistics Agency. Zimbabwe Population Census 2012. Government of Zimbabwe, Harare

[5] Z. Berge, \& L. Muilenburg, (2013). Handbook of mobile learning. London: Routledge.

[6] J Traxler, \& A. Kukulska-Hulme, (2016). Mobile learning: the next generation. London: Routledge.

[7] S. Caballé, L. Barolli and F. Xhafa, Using Mobile Devices to Support Online Collaborative Learning, Mobile Information Systems - January 2010
[8] J. Traxler, (2007). Defining, Discussing and Evaluating Mobile Learning: The moving finger writes and having writ. The International Review of Research in Open and Distance Learning, 8(2).

[9] S.S. Liaw, M. Hatala, \& H. M. Huang, (2010). Investigating acceptance toward mobile learning to assist individual knowledge management: Based on activity theory approach. Computers \& Education, 54(2), 446-454

[10] M. Cinque, (2013). The "Reflective Student": The use of Mobile Devices Through Seamless Educational Spaces and Authentic Learning Scenarios. In Z. L. Berge \& L. Muilenburg (Eds.), Handbook of Mobile Education (pp. 209-223). New York, NY: Routledge

[11] M. Kearney, S. Schuck, K. Burden, \& P. Aubusson, (2012). Viewing mobile learning from a pedagogical perspective. Research in Learning Technology, 20

\section{AUTHORS}

Servious Mbiza, Master of Commerce in Information Systems, Zimbabwe Open University, mbizas@ zou.ac.zw, smsmbiza@gmail.com, +263773004225 